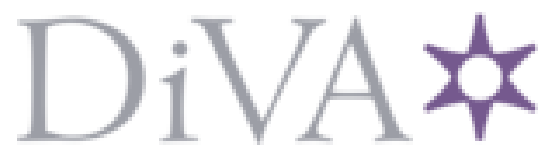

http://www.diva-portal.org

This is the published version of a paper published in .

Citation for the original published paper (version of record):

liu, P., Gardner, J., Kloo, L. (2017)

Cross-linked sulfur-selenium polymers as hole transporting materials in dye-sensitized solar cells and perovskite solar cells,.

Access to the published version may require subscription.

N.B. When citing this work, cite the original published paper.

Permanent link to this version:

http://urn.kb.se/resolve?urn=urn:nbn:se:kth:diva-211088 


\title{
Cross-Linked Sulfur-Selenium Polymers as Hole- Transporting Materials in Dye-Sensitized Solar Cells and Perovskite Solar Cells
}

\author{
Peng Liu, Lars Kloo, and James M. Gardner*a]
}

Novel inverse-vulcanized polymeric sulfur-selenium materials
$\left(\mathrm{SeS}_{2}: \mathrm{S}: \mathrm{DIB}\right.$, where $\mathrm{DIB}=1,3$-diisopropenylbenzene) have been
prepared and utilized for solid-state dye-sensitized solar cells
and perovskite solar cells. Under standard AM $1.5 \mathrm{G}$ illumination
$\left(1000 \mathrm{~W} \mathrm{~m}^{-2}\right)$, a power conversion efficiency of $1.70 \%$ was re-
corded for polymeric sulfur-selenium-based $\left(\mathrm{SeS}_{2}: \mathrm{S}: \mathrm{DIB}\right)$ solid-
state solar cells, which is higher than that of polymeric sulfur-
based (S:DIB) devices (1.09\%). For perovskite solar cells, a rela-
tively high efficiency has been achieved for polymeric sulfur-
selenium-based $\left(\mathrm{SeS}_{2}: \mathrm{S}: \mathrm{DIB}\right)$ solar cells $(10.21 \%)$ and polymeric sulfur-based (S:DIB; 7.32\%) solar cells, respectively. The conductivity of the polymeric SeS material has been determined to $2.24 \times 10^{-4} \mathrm{Scm}^{-1}$, which is higher than for the polymeric sulfur material under the same doping conditions. Photoinduced absorption and steady-state photoluminescence measurements were performed to investigate the charge-transfer properties relevant for the solar cells. The results in the present study qualify the new polymeric sulfur-selenium materials as candidates for low-cost hole-transport materials for photovoltaic devices.

\section{Introduction}

The transition from a fossil-fuel-based energy system to a solar-energy-based energy system is dependent on reducing the overall cost of making, using, and replacing photovoltaics. Possible means to reduce overall costs include increasing energy conversion efficiency, decreasing the cost of fabrication, as well as decreasing the inherent cost of materials for the production of the solar cells. Thus, the design and identification of abundant and inexpensive materials represents a major scientific challenge. Solid-state photovoltaics, such as solid-state dye-sensitized solar cells (ssDSSCs) and organic-inorganic metal halide perovskite solar cells (PSCs), are promising alternatives for replacing traditional silicon-based solar technologies. ${ }^{[1,2]}$ In general, those devices consist of two electrodes in electrical contact through a solid electrolyte system. In the above systems, the hole-transporting material (HTM) plays the essential role of hole-selective charge transport to the counter electrode. An ideal HTM should be easy to process (high solubility in organic solvents), be synthesized from inexpensive and abundant starting materials, display a high hole conductivity, and exhibit good thermal and photochemical stability. When producing relatively efficient solar cells, the most commonly used HTM (Spiro-OMeTAD) costs roughly 250 thousand

[a] P. Liu, Prof. L. Kloo, Dr. J. M. Gardner

Division of Applied Physical Chemistry

Department of Chemistry

KTH-Royal Institute of Technology

Teknikringen 30

10044 Stockholm (Sweden)

E-mail:jgardner@kth.se

(D)

Supporting Information and the ORCID identification number(s) for the

author(s) of this article can be found under:

https://doi.org/10.1002/cptc.201700037. dollars per kilogram on the current market. In response to the high cost of Spiro-OMeTAD, significant effort has been recently put into the design of low-cost alternative hole-transport materials for ssDSSCs and PSCs. Kim and co-workers introduced in situ solid-state polymerization of conducting polymers for highly efficient ssDSSCs. ${ }^{[3]} \mathrm{Xu}$ et al. developed a triphenylamine-based oligomer hole-transport material for $\operatorname{ssDSSC~}^{[4]}$ and carbazole-based HTMs for PSCs. ${ }^{[5]}$ Recently, a comparatively low-cost spiro[fluorene-9,9'-xanthene] (SFX) based organic hole-transport material (HTM) termed X60 has been applied in ssDSSCs and PSCs with efficiencies of $7.30 \%$ and $19.84 \%$, respectively. ${ }^{[6]}$ Hua et al. have designed fluorene-based HTMs and achieved efficiencies of $6.35 \%$ for ssDSSCs and $18.04 \%$ for PSCs, respectively, with $\mathrm{HT} 2$ as the HTM. ${ }^{[7]}$ Recently, Zhang, et al. studied the effect of alkyl chains of organic HTMs for efficient perovskite solar cells with reported efficiencies up to $17.33 \%{ }^{[8]}$ On the other hand, inorganic hole-transport materials for solid-state photovoltaics have also been developed. Copper-based p-type inorganic semiconductors have been reported as hole-transport materials for $\operatorname{ssDSSCs}^{[9,10]}$ and PSCs. ${ }^{[11,12]}$ The element of sulfur is an abundant and inexpensive material. Due to its unique electrochemical properties and high natural abundance, sulfur or polysulfides have become widely utilized in efficient lithium batteries ${ }^{[13-16]}$ and in thin-film photovoltaic devices. ${ }^{[17-19]}$ Initially, Pyun and co-workers designed co-polymerization strategies to synthesize novel solution-processable sulfur-based polymers by co-polymerization with divinylic co-monomers. ${ }^{[20]}$ Recently, we demonstrated the use of polymeric sulfur in a stable, cross-linked material as a hole-transport material in ssDSSCs. ${ }^{[21]}$ However, one of the drawbacks of polymeric sulfur is the low hole conductivity. In our present studies, we have successfully introduced selenium 
into cross-linked polymeric sulfur in order to increase the electrical conductivity, thus enhancing the performance of the solar cell devices. Similar materials were just recently prepared by Boyd and co-workers, although their focus was on thermal stability and infrared spectroscopy. ${ }^{[22]}$

\section{Experimental Section}

\section{Synthesis of Cross-Linked Polymeric Sulfur and Cross-Linked Selenium-Doped Polymeric Sulfur}

All chemicals were purchased from Sigma-Aldrich unless otherwise indicated. The photosensitizer for ssDCS (LEG4) was acquired from Dyenamo $A B{ }^{[23]}$ The synthesis of the cross-linked polymeric sulfur (S:DIB) closely followed literature ${ }^{[20]}$ and is summarized below. The weight ratio of S:DIB used was 1:1 for the cross-linked polymeric sulfur. For cross-linked polymeric sulfur doped with selenium, elemental sulfur was heated to $185^{\circ} \mathrm{C}$ to form a molten sulfur liquid (working as solvent). Then the $\mathrm{SeS}_{2}(99 \%)$ was added into the liquid sulfur solvent. The mixture was stirred for $2 \mathrm{~min}$. Subsequently, 1,3-diisopropenylbenzene (DIB) was directly added into the mixture and allowed to react for $10 \mathrm{~min}$. The weight ratio of $\mathrm{SeS}_{2}: \mathrm{S}: \mathrm{DIB}$ was 1:1:1.

\section{Device Fabrication}

Fluorine-doped tin dioxide (FTO) substrates (Pilkington TEC15) were dipped into a $\mathrm{Zn}-\mathrm{HCl}$ solution $\left(15 \mathrm{mg} \mathrm{cm}^{-2}\right.$ zinc powder and $2 \mathrm{~m}$ hydrochloric acid) for etching. After that step, the substrates were cleaned in an ultrasonic bath using deionized water (15 min), acetone (30 $\mathrm{min})$, and ethanol (30 min), respectively. A spray pyrolysis deposition (SPD) technique was applied to obtain a compact layer of $\mathrm{TiO}_{2}$ as a blocking layer on top of the FTO substrate. The solution used in the SPD process was $0.2 \mathrm{M}$ titanium(IV) isopropoxide and $2 \mathrm{M}$ acetylacetone in isopropanol. For manufacturing of the ssDSSCs, a $\mathrm{TiO}_{2}$ paste (Dyesol DSL 18NR-T) mixed with ethanol (3:1 mass ratio) was deposited on the compact layer of $\mathrm{TiO}_{2}$ using spin coating. After sintering on a hotplate at $500^{\circ} \mathrm{C}$ for $30 \mathrm{~min}$ and cooling to room temperature, the substrate $\left(2 \mathrm{mg} \mathrm{mL}^{-1}\right)$ was immersed into a solution of $0.2 \mathrm{M}$ aqueous $\mathrm{TiCl}_{4}$ at $70^{\circ} \mathrm{C}$ for $30 \mathrm{~min}$. Then, the substrates were rinsed with deionized water and ethanol, then annealed on a hotplate at $500^{\circ} \mathrm{C}$ for $30 \mathrm{~min}$. After being cooled to $90^{\circ} \mathrm{C}$, the hot $\mathrm{TiO}_{2}$ film was immersed into an ethanol bath of the photosensitizer ( $0.2 \mathrm{~mm}$ LEG4) for $18 \mathrm{~h}$. After the sensitization, the electrodes were rinsed with ethanol and dried in an $\mathrm{N}_{2}$ gas flow. The surfaces of the dried substrates were covered by a S:DIB or $\mathrm{SeS}_{2}: \mathrm{S}: \mathrm{DIB}$ HTM solution $\left(10 \mathrm{mg} \mathrm{mL}^{-1}\right)$ containing additives (Li[TFSI] $120 \mathrm{~mm}$ and TBP $200 \mathrm{~mm}$; LI[TFSI] = lithium bistrifluoromethanesulfonimidate; $\mathrm{TBP}=4$-tert-butylpyridine) for $30 \mathrm{sec}$ and then spin-coated for $30 \mathrm{sec}$ at $2000 \mathrm{rpm}$ to form a uniform HTM layer. Afterwards, the cells were left in air overnight in the dark and a $200 \mathrm{~nm}$ thick Ag layer was deposited on the top of the HTM layer by thermal evaporation in a vacuum chamber (Leica EM MED020).

The mixed perovskite precursor solution was prepared by dissolving $\left(\mathrm{NH}_{2} \mathrm{CH}_{2} \mathrm{NH}_{2}\right) \mathrm{I}(1 \mathrm{M} ; \mathrm{FAI}), \mathrm{Pbl}_{2}(1.1 \mathrm{M}), \mathrm{CH}_{3} \mathrm{NH}_{3} \mathrm{Br}(0.2 \mathrm{M}, \mathrm{MABr})$ and $\operatorname{PbBr}_{2}(0.2 \mathrm{M})$ in the anhydrous mixed solvent DMF:DMSO 4:1 volume ratio. $\mathrm{A}\left(\mathrm{FAPbl}_{3}\right)_{0.85}\left(\mathrm{MAPbBr}_{3}\right)_{0.15}$ layer was formed on the $\mathrm{TiO}_{2}$ layer through spin coating of the mixed perovskite precursor solution in a two-step program at 1000 and $4000 \mathrm{rpm}$ for 10 and $30 \mathrm{sec}$, respectively. During the second step, $125 \mu \mathrm{L}$ of chlorobenzene was poured on the spinning substrate $15 \mathrm{sec}$ prior to the end of the program. The substrates were then annealed at $100^{\circ} \mathrm{C}$ for $45 \mathrm{~min}$. Subsequently, the S:DIB or $\mathrm{SeS}_{2}: S: D I B$ HTM layer $\left(10 \mathrm{mg} \mathrm{mL}^{-1}\right.$ ) with additives (Li[TFSI] $30 \mathrm{~mm}$ and TBP $200 \mathrm{~mm}$ ) was spin-coated on top of the perovskite film. Finally, a layer of $80 \mathrm{~nm}$ $\mathrm{Au}$ was deposited sequentially under high vacuum $\left(<4 \times 10^{-5} \mathrm{~Pa}\right)$ by thermal evaporation through a shadow mask to form an active area of $\approx 20 \mathrm{~mm}^{2}$.

\section{Device Characterization}

Current-voltage $(J-V)$ characteristics of the solar-cell devices were recorded under $100 \mathrm{~mW} \mathrm{~cm}^{-2}$ (AM 1.5G) with a Keithlley Model 2400 source meter. The light source was calibrated by a certified reference solar cell (Fraunhofer ISE) for an intensity of $100 \mathrm{~mW} \mathrm{~cm}^{-2}$. A black mask with an aperture area of $0.126 \mathrm{~cm}$ was placed on the top of the cell during the measurements. Incident photon-to-current conversion efficiency (IPCE) spectra were recorded by a computer-controlled setup comprised of a Xenon lamp (Spectral Products ASB-XE-175), a monochromator (Spectral Products CM110) and a Keithley multimeter (Model 2700), and calibrated by a certified reference solar cell (Fraunhofer ISE). The electron lifetime measurements were recorded through monitoring photovoltaic transients at different light intensities by applying a small square-wave modulation to a base light intensity. The photovoltaic response was fitted using first-order kinetics in order to obtain the time constants.

\section{Photoinduced Absorption Spectroscopy}

The solar cell device samples used in photoinduced absorption (PIA) measurements were prepared as described above but without the final Ag contact layer. PIA spectra were recorded on a homemade setup, which has been described previously. ${ }^{[24]} \mathrm{A}$ $20 \mathrm{~W}$ tungsten-halogen lamp, filtered up to $530 \mathrm{~nm}$, generated a "white" probe light. A square-wave modulated (on-off) blue LED light source $\left(460 \mathrm{~nm}\right.$ light with $6.1 \mathrm{~mW} \mathrm{~cm}^{-2}$ intensity and $9.3 \mathrm{~Hz}$ modulation frequency) was used for excitation. The transmitted probe light was focused onto a monochromator and detected by a UV-enhanced silicon and germanium photodiode detector.

\section{UV/Vis Absorption and Photoluminescence}

UV/Vis absorption measurements were performed using a Lambda $750 \mathrm{UV} / \mathrm{Vis}$ spectrophotometer. The $\mathrm{FTO} / \mathrm{TiO}_{2}$ substrate signal was used as a background calibration. The thickness of the mesoporous $\mathrm{TiO}_{2}$ film was around $500 \mathrm{~nm}$. The photoluminescence spectra of the perovskite thin films were recorded on a Cary Eclipse fluorescence spectrophotometer with excitation at $550 \mathrm{~nm}$.

\section{Conductivity}

Glass substrates without a conductive layer were carefully cleaned following the method for FTO substrates. A thin layer of mesoporous $\mathrm{TiO}_{2}$ was coated on the glass substrates by spin-coating a diluted $\mathrm{TiO}_{2}$ paste (Dyesol DSL 18NR-T) with terpineol (1:3, mass ratio). The thickness of the film is ca. $500 \mathrm{~nm}$, as measured with a DekTak profilometer. The concentrations of the S:DIB and $\mathrm{SeS}_{2}: \mathrm{S}$ :DIB solutions used as HTMs were the same as in the manufacturing of the photovoltaic devices. J-V characteristics were recorded on a Keithley 2400 Semiconductor Characterization System. Measurements were carried out following the procedure described in a previously published paper. ${ }^{[25]}$ 


\section{Results and Discussion}

\subsection{UV/Vis Absorption}

Figure 1 shows the UV/Vis absorption spectra of cross-linked polymeric sulfur (S:DIB) and Se-doped polymeric sulfur $\left(\mathrm{Se}_{2}: \mathrm{S}: \mathrm{DIB}\right)$ in toluene solutions. As discussed in our previous paper, ${ }^{[21]}$ the peaks between $\lambda=430 \mathrm{~nm}$ and $620 \mathrm{~nm}$ can be assigned to different polymeric sulfur radicals. ${ }^{[26,27]}$ After doping of selenium into the inorganic polymer, the absorption range extends to $\approx 700 \mathrm{~nm}$. The earlier onset in the absorption spectrum of $\mathrm{SeS}_{2}: \mathrm{S}: \mathrm{DIB}$ system indicates that the inclusion of selenium in the cross-linked polymeric sulfur reduces the band gap of the inorganic polymer. A much broader set of absorption peaks is observed between $450 \mathrm{~nm}$ and $650 \mathrm{~nm}$ for $\mathrm{SeS}_{2}: \mathrm{S}: \mathrm{DIB}$, which could be assigned to the presence of direct $\mathrm{Se}-\mathrm{Se}$ bonding. ${ }^{[28]}$

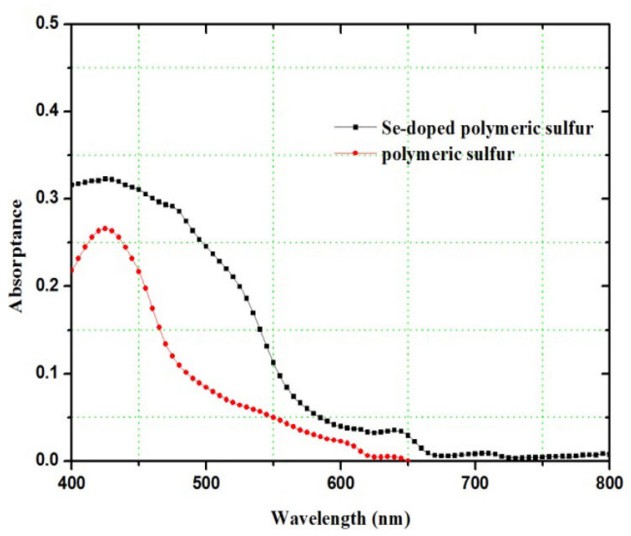

Figure 1. UV/Vis absorption spectra of cross-linked polymeric sulfur (S:DIB) and cross-linked Se-doped polymeric sulfur $\left(\mathrm{SeS}_{2}: \mathrm{S}: \mathrm{DIB}\right)$ in toluene solution (2 $\left.\mathrm{mg} \mathrm{mL}^{-1}\right)$.

\subsection{Conductivity}

Most likely, the largest limiting factor with respect to efficient conversion of solar light in ssDSSCs can be traced to a low charge-carrier mobility of the hole-transport material itself. Figure 2 shows the Tafel plot of the polymeric S:DIB and $\mathrm{SeS}_{2}: \mathrm{S}:$ DIB doped with Li[TFSI]. As showed in our previous paper ${ }^{[21]}$ the conductivity of polymeric sulfur is shown to be 10-100 lower than for, the so far best performing hole-transport material, doped Spiro-OMeTAD. ${ }^{[29]}$ When the concentration of Li[TFSI] in the spin-coating solution is increased to $120 \mathrm{~mm}$, the conductivity of polymeric sulfur can be increased to $6.13 \times 10^{-5} \mathrm{Scm}^{-1}$. With inclusion of selenium in the polymeric sulfur, the conductivity can be increased to $2.24 \times$ $10^{-4} \mathrm{Scm}^{-1}$. The incorporation of selenium into the crosslinked sulfur polymer worked as intended and conductivity increased by a factor of 3.5 with respect to the pure sulfur polymer. The modest gain in conductivity suggests that the focus of future research on increasing the efficiency of these types of solar cells should be on further increasing conductivity by

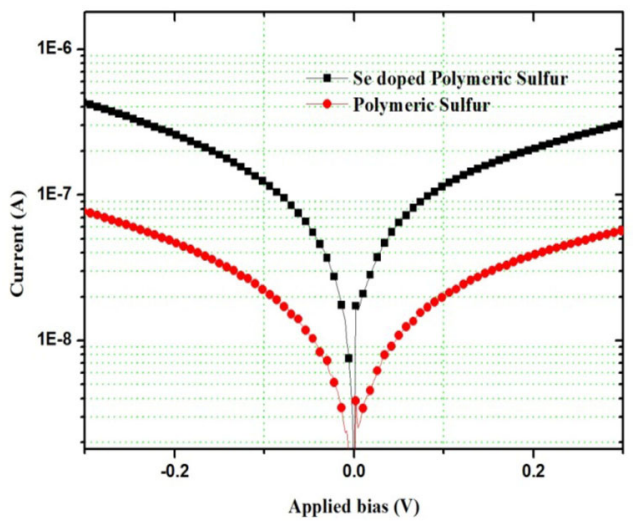

Figure 2. Current-voltage characteristics of the polymeric $\mathrm{SeS}_{2}: \mathrm{S}: \mathrm{DIB}$ (black) and S:DIB (red) films doped with Li[TFSI].

more efficient deposition and optimization of device fabrication.

\subsection{Characterization of ssDSSC Devices}

\subsubsection{J-V Characteristics and IPCE}

Figure 3 shows $J-V$ curves of ssDSSCs based on the S:DIB and $\mathrm{SeS}_{2}: \mathrm{S}$ :DIB hole-transporting materials under different irradiation conditions. The photovoltaic parameters of the ssDSSC devices are summarized in Table 1 and device statistics have been collected in the Supporting Information (Figure S2). Upon illumination at standard 1 sun light intensity, the devices based on polymeric $\mathrm{SeS}_{2}: \mathrm{S}: \mathrm{DIB}$ yield an efficiency of $1.70 \%$ together with a $J_{\mathrm{sc}}$ value of $5.04 \mathrm{mAcm}^{-2}$, a fill factor (FF) of 0.45 , and $V_{\text {oc }}$ value of $750 \mathrm{mV}$, as compared to an efficiency of $1.09 \%$ for devices based on polymeric S:DIB alone. The efficiency for devices based on S:DIB is slightly lower than the previously reported ${ }^{[21]}$ which can be due to different ambient environment conditions during device fabrication. Under low-light conditions ( $5 \%$ of 1 sun light intensity) the devices based on polymeric SeS $\left(\mathrm{SeS}_{2}: \mathrm{S}: \mathrm{DIB}\right)$ showed a $V_{\text {oc }}$ value of $650 \mathrm{mV}$, a $J_{\text {sc }}$ value

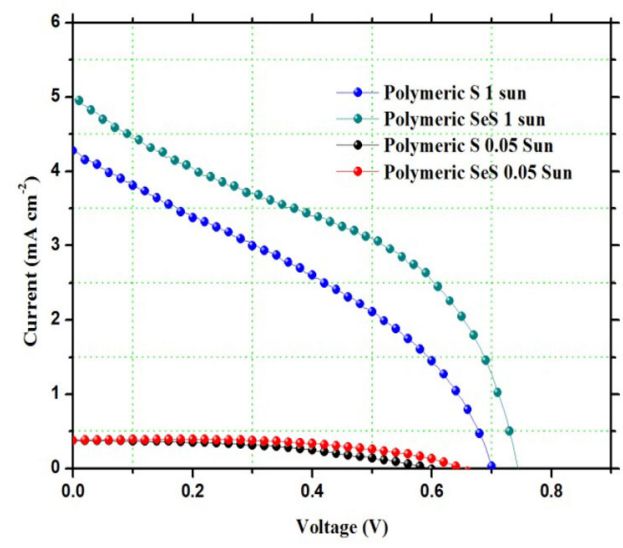

Figure 3. The $J-V$ characteristics of ssDSSCs based on LEG4 in combination with cross-linked polymeric sulfur (S:DIB) and Se-doped sulfur $\left(\mathrm{SeS}_{2}: \mathrm{S}: \mathrm{DIB}\right)$ as hole-transport materials. 
Table 1. Photovoltaic parameters of ssDSSC devices based on crosslinked polymeric $\mathrm{S}: \mathrm{DIB}$ and $\mathrm{SeS}_{2}: \mathrm{S}: \mathrm{DIB}$ under different light intensities.

\begin{tabular}{|lllll|} 
S:DIB & $V_{\text {oc }}[\mathrm{mV}]$ & $J_{\text {sc }}\left[\mathrm{mAcm}^{-2}\right]$ & $\mathrm{FF}$ & $\eta[\%]$ \\
\hline 1 Sun & 700 & 4.34 & 0.361 & 1.09 \\
0.05 Sun & 595 & 0.37 & 0.46 & 2.06 \\
SeS $:$ S:DIB & & & & \\
1 Sun & 750 & 5.04 & 0.45 & 1.70 \\
0.05 Sun & 650 & 0.37 & 0.55 & 2.67 \\
\hline
\end{tabular}

of $0.37 \mathrm{~mA} \mathrm{~cm}^{-2}$, and a fill factor of 0.55 , yielding an overall excellent efficiency of $2.67 \%$. The devices based on polymeric S:DIB yielded an efficiency of $2.06 \%$ under $5 \%$ of 1 sun intensity, with $J_{\mathrm{sc}}=0.37, V_{\mathrm{oc}}=595 \mathrm{mV}$ and fill factor of 0.46 , respectively. Under the same conditions, there is an obvious increase in efficiencies for devices based on the Se-doped HTM in comparison to that based on polymeric sulfur. The higher conversion efficiencies obtained at lower illumination clearly show that charge transport in the HTM represents a significant bottleneck towards higher overall conversion efficiencies. In order to study the external quantum efficiencies, incident photon-tocurrent conversion efficiencies (IPCE) have been determined (Figure 4). Maximum monochromatic conversion efficiencies of $41 \%$ for $\mathrm{SeS}_{2}: \mathrm{S}:$ DIB-based devices and $37 \%$ for S:DIB-based devices are located at around $500 \mathrm{~nm}$. The range of IPCE spectra is in good agreement with UV/Vis absorption spectra of the LEG4 dye on $\mathrm{TiO}_{2}$.

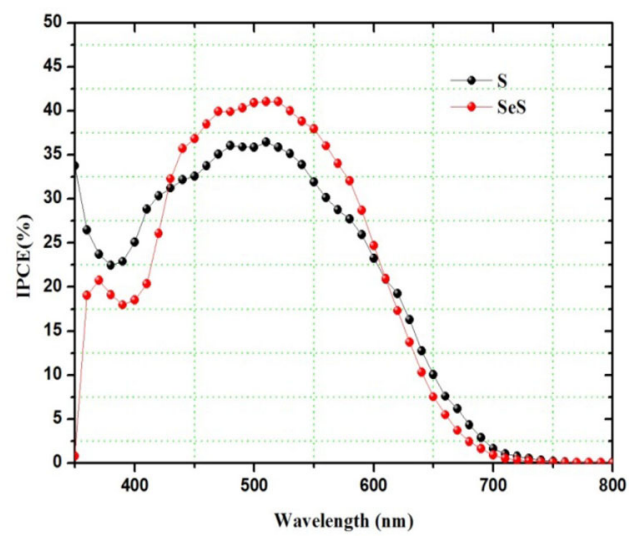

Figure 4. The IPCE spectra of ssDSSCs based on cross-linked polymeric sulfur (S:DIB; black) and polymeric Se-doped sulfur $\left(\mathrm{SeS}_{2}: \mathrm{S}: \mathrm{DIB}\right.$; red) as hole-transporting materials.

\subsubsection{PIA}

In order to study the charge-transfer process between the LEG4 dyes and the polymeric hole-transport materials, photoinduced absorption (PIA) spectroscopy was performed. As seen in Figure 5, after excitation of LEG4 on $\mathrm{TiO}_{2}$ with blue light, a bleach is observed between $525-625 \mathrm{~nm}$ and new absorption bands emerge between $625-850 \mathrm{~nm}$. These changes in absorption are attributable to the ground-state bleach of LEG4 and absorption of oxidized LEG4, respectively. ${ }^{[29,30]}$ After deposition of the S:DIB and $\mathrm{SeS}_{2}: \mathrm{S}: \mathrm{DIB}$ HTMs onto the LEG4-sensi-

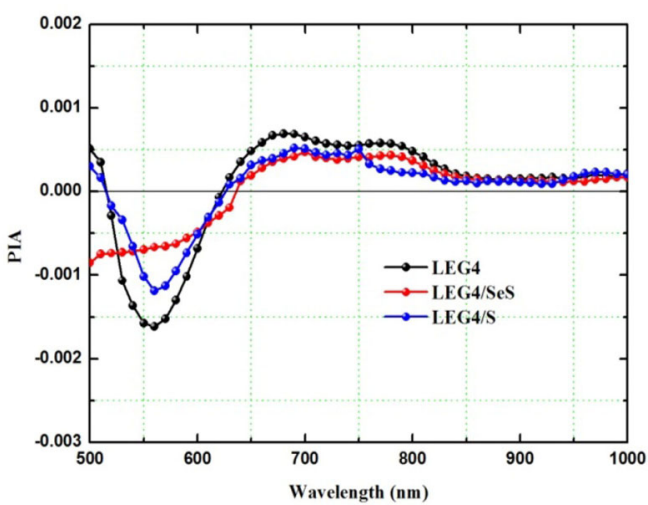

Figure 5. Photoinduced absorption spectra of ssDSSC devices containing $\mathrm{S}$ :DIB (LEG4/S; blue) or $\mathrm{SeS}_{2}$ :S:DIB (LEG4/SeS; red) as hole-transport materials, or no hole-transport material (LEG4; black).

tized $\mathrm{TiO}_{2}$, the PIA spectra show a decrease in the LEG4 ground-state bleach, as well as a decrease in the absorption from oxidized LEG4. These changes represent clear indications of dye regeneration. The differences in the PIA spectra for the $\mathrm{S}: \mathrm{DIB}$ and $\mathrm{SeS}_{2}: \mathrm{S}: \mathrm{DIB}$ samples can be related to the differences in the absorption spectra of the two materials: Increased absorption at longer wavelengths and throughout the visible by $\mathrm{SeS}_{2}: S$ :DIB relative to S:DIB leads to a broader ground-state bleach. All results indicate that a charge transfer takes place between sensitizers and HTM layers (i.e. the dye is regenerated) for both the HTMs in this study.

\subsection{Characterization of PSC Devices}

Recently, organic-inorganic metal halide perovskite solar cells (PSCs), from which the perovskite $\mathrm{CH}_{3} \mathrm{NH}_{3} \mathrm{Pbl}_{3}$ is the prototypical example, have shown potential to be a breakthrough technology in field of photovoltaics. In particular, mixed-ion perovskite solar cells utilizing combinations of halides $\left(\mathrm{Br}^{-}\right.$and $\left.\mathrm{I}^{-}\right)$ and cations $\left(\mathrm{NH}_{2} \mathrm{CH}_{2} \mathrm{NH}_{2}{ }^{+}\right.$and $\left.\mathrm{CH}_{3} \mathrm{NH}_{3}{ }^{+}\right)$have attracted much attention due to the high efficiencies and easy fabrication. ${ }^{[6,8,31]}$ In the following section, we will discuss the applications of cross-linked sulfur-based polymeric materials in PSCs based on the commonly used perovskite $\mathrm{FA}_{0.85} \mathrm{MA}_{0.15} \mathrm{~Pb}\left(\mathrm{I}_{0.85} \mathrm{Br}_{0.15}\right)_{3}$.

\subsubsection{J-V Characteristics and IPCE}

Figure 6 shows the $J-V$ characteristics of PSCs based on polymeric S:DIB and $\mathrm{SeS}_{2}: \mathrm{S}:$ DIB hole-transport materials for different scan directions. The photovoltaic parameters of the PSC devices are summarized in Table 2 and statistical data are presented in the Supporting Information. For the forward direction scan (from $V_{\text {oc }}$ to $J_{\text {sc }}$ ), the PSCs based on polymeric $\mathrm{SeS}_{2}$ :S:DIB show an efficiency of $10.11 \%$ with a $V_{\text {oc }}$ value of $870 \mathrm{mV}$ a $J_{\mathrm{sc}}$ value of $22.79 \mathrm{mAcm}^{-2}$, and a fill factor (FF) of 0.51 . For the reverse direction (from $J_{\text {sc }}$ to $V_{o c}$ ), the efficiency for devices based on polymeric $\mathrm{SeS}_{2}: \mathrm{S}: \mathrm{DIB}$ is $8.61 \%$, with $V_{\text {oc }}=$ $880 \mathrm{mV}, J_{\mathrm{sc}}=22.07 \mathrm{mAcm}^{-2}$ and an FF of 0.43 , respectively. In the case of polymeric sulfur-based PSCs, the efficiencies amounted to $7.32 \%\left(J_{\mathrm{sc}}=21.78 \mathrm{mAcm}^{-2}, V_{\mathrm{oc}}=800 \mathrm{mV}, \mathrm{FF}=\right.$ 


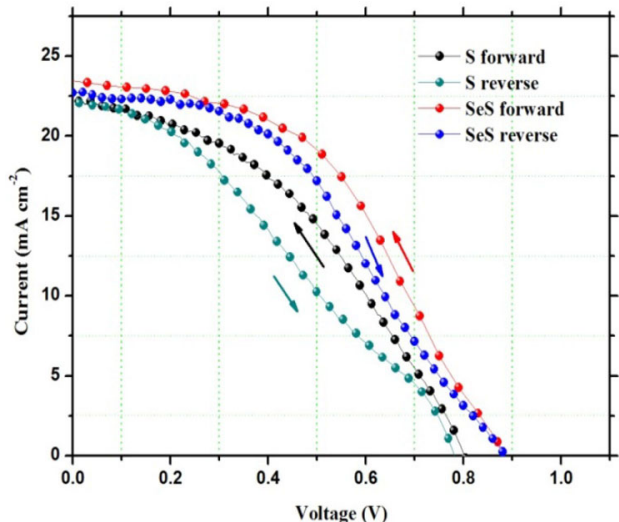

Figure 6. The $J-V$ characteristics of mixed-ion perovskite solar cells based on cross-linked polymeric sulfur and Se-doped sulfur (SeS) materials as holetransport material studied under 1 sun illumination.

Table 2. Photovoltaic parameters of the best performing PSC devices based on polymeric S:DIB and $\mathrm{SeS}_{2}: \mathrm{S}: \mathrm{DIB}^{\left[{ }^{[a]}\right.}$

\begin{tabular}{lllll|} 
S:DIB & $V_{\text {oc }}[\mathrm{mV}]$ & $J_{\text {sc }}\left[\mathrm{mAcm}^{-2}\right]$ & $\mathrm{FF}$ & $\eta[\%]$ \\
\hline Forward & 800 & 21.78 & 0.42 & 7.32 \\
Reverse & 778 & 21.97 & 0.33 & 5.66 \\
SeS & :S:DIB & & & \\
Forward & 870 & 22.79 & 0.51 & 10.11 \\
Reverse & 880 & 22.07 & 0.43 & 8.61 \\
\hline
\end{tabular}

[a] Scan rate $200 \mathrm{mV} \mathrm{s}^{-1}$, statistics on devices shown in the Supporting Information.

$0.42)$ in the forward direction scan, and $5.66 \% \quad\left(J_{\mathrm{sc}}=\right.$ $21.97 \mathrm{mAcm}^{-2}, V_{\mathrm{oc}}=778 \mathrm{mV}, \mathrm{FF}=0.33$ ) in the reverse direction scan. In both cases, the cross-linked polymeric $\mathrm{S}$ and Se/S materials worked well as hole-transport materials, even though substantial hysteresis was observed. The hysteresis phenomena may be affected by the relatively low conductivity of the polymers. Despite the conductivity problems, both polymers showed surprisingly high short circuit current densities. These promising results highlight the potential use of sulfur and selenium polymers as low-cost hole-transporting materials for solar cells. According to the XRD results shown in Figure S5, our perovskite was predominantly the alpha phase of the mixed-ion perovskite solar cell although it contained a small fraction of $\mathrm{FAPbl}_{3}$ as an impurity. These impurities may have decreased overall power conversion efficiencies to some extent. The incident photon-to-current conversion efficiency (IPCE) spectra (Figure 7), indicate that despite the polymers' strong light absorption in the visible region, there is no impediment of the light harvesting by the perovskite. A maximum monochromatic conversion efficiency of $75 \%$ for $\mathrm{SeS}_{2}: S:$ DIB based devices and $70 \%$ for S:DIB based devices are located at around $480 \mathrm{~nm}$, with a slight decrease in efficiency notable just under $750 \mathrm{~nm}$. The range of the IPCE spectra is in good agreement with the absorption spectra of mixed-ion perovskite materials in solar cells.

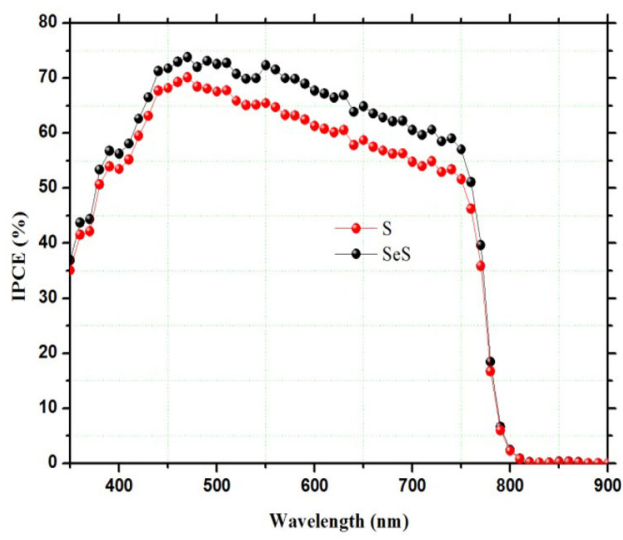

Figure 7. The IPCE spectra of mixed-ion perovskite based solar cells in combination with cross-linked polymeric sulfur (S:DIB; red) and Se-doped sulfur $\left(\mathrm{SeS}_{2}: \mathrm{S}: \mathrm{DIB}\right.$; black) as hole-conductor materials.

\subsubsection{Photoluminescence (PL)}

In order to get further insights into the charge-transfer properties at the interface of the perovskite/HTM, steady-state photoluminescence was recorded (Figure 8). The presence of the cross-linked sulfur and selenium-doped sulfur polymers partially quenches the photoluminescence of the perovskite thin film as compared to that of the pristine perovskite film. The results suggest that hole transfer to the HTMs occurs from the excited state of the perovskite even in the presence of $\mathrm{TiO}_{2}$. A small band in the photoluminescence spectra is found at $\lambda=$ $825 \mathrm{~nm}$, which can be assigned to $\mathrm{FAPbl}_{3}$. This is consistent with the XRD data, which also indicates the presence of $\mathrm{FAPbl}_{3}$ as an impurity in the perovskite films.

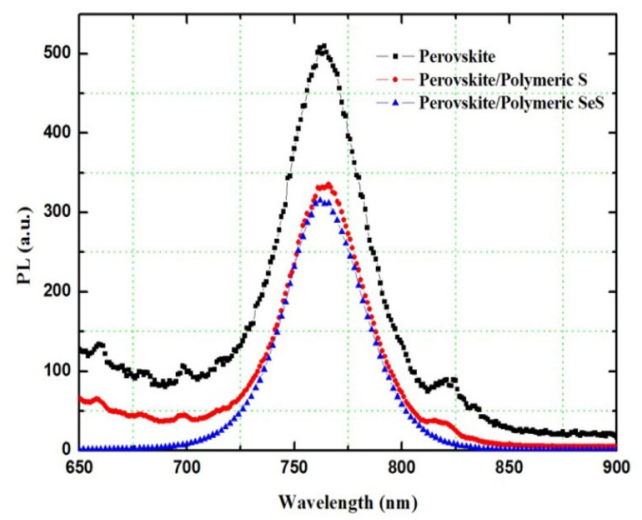

Figure 8. Steady-state photoluminescence spectra of perovskite thin films in the absence of HTM (black), and in the presence of S:DIB (red) and $\mathrm{SeS}_{2}: \mathrm{S}$ :DIB (blue) HTMs.

\section{Conclusions}

In conclusion, we have applied a new class of hole-transport materials based on the abundant element sulfur in solid-state DSSCs and perovskite solar cells. Both kinds of devices based on selenium-doped polymeric sulfur as hole-transporting mate- 
rial show surprisingly good power conversion efficiencies. The PIA and PL measurements indicate that efficient charge transfer occurs between the hole-transport materials and working electrodes. However, low photocurrents in SsDSC and poor fill factors may be traced to the limited HTM conductivity as well as incomplete pore filling of the mesoporous $\mathrm{TiO}_{2}$ substrate. Nevertheless, the current results offer a new and promising line of research aimed at efficient and low-cost materials that offer possibilities for large-scale production. This research may guide the development of sulfur-based materials for solid-state photovoltaics and other optoelectronic applications.

\section{Acknowledgements}

The authors would like to thank the Swedish Research Council, the Swedish Energy Agency and the Knut \& Alice Wallenberg Foundation for financial support. J.G. would like to kindly acknowledge the support of the Swedish Government through the research initiative "STandUP for ENERGY".

\section{Conflict of interest}

The authors declare no conflict of interest.

Keywords: conducting materials • energy conversion selenium · solar cells · sulfur

[1] B. O'Regan, M. Gratzel, Nature 1991, 353, 737-740.

[2] A. Hagfeldt, G. Boschloo, L. Sun, L. Kloo, H. Pettersson, Chem. Rev. 2010, $110,6595-6663$.

[3] J. K. Koh, J. Kim, B. Kim, J. H. Kim, E. Kim, Adv. Mater. 2011, 23, 1641 1646.

[4] B. Xu, H. Tian, D. Bi, E. Gabrielsson, E. M. J. Johansson, G. Boschloo, A. Hagfeldt, L. Sun, J. Mater. Chem. A 2013, 1, 14467-14470.

[5] B. Xu, E. Sheibani, P. Liu, J. Zhang, H. Tian, N. Vlachopoulos, G. Boschloo, L. Kloo, A. Hagfeldt, L. Sun, Adv. Mater. 2014, 26, 6629-6634.

[6] B. Xu, D. Bi, Y. Hua, P. Liu, M. Cheng, M. Gratzel, L. Kloo, A. Hagfeldt, L. Sun, Energy Environ. Sci. 2016, 9, 873-877.

[7] Y. Hua, J. Zhang, B. Xu, P. Liu, M. Cheng, L. Kloo, E. M. J. Johansson, K. Sveinbjörnsson, K. Aitola, G. Boschloo, L. Sun, Nano Energy 2016, 26, $108-113$.

[8] J. Zhang, B. Xu, M. B. Johansson, M. Hadadian, J. P. Correa Baena, P. Liu, Y. Hua, N. Vlachopoulos, E. M. J. Johansson, G. Boschloo, L. Sun, A. Hagfeldt, Adv. Energy Mater. 2016, 6, 1502536.

[9] B. O'Regan, F. Lenzmann, R. Muis, J. Wienke, Chem. Mater. 2002, 14, 5023-5029.
[10] K. Tennakone, G. R. R. A. Kumara, A. R. Kumarasinghe, K. G. U. Wijayantha, P. M. Sirimanne, Semicond. Sci. Technol. 1995, 10, 1689.

[11] J. A. Christians, R. C. M. Fung, P. V. Kamat, J. Am. Chem. Soc. 2014, 136, $758-764$.

[12] P. Qin, S. Tanaka, S. Ito, N. Tetreault, K. Manabe, H. Nishino, M. K. Nazeeruddin, M. Grätzel, Nat. Commun. 2014, 5, 3834.

[13] J. Wang, J. Yang, C. Wan, K. Du, J. Xie, N. Xu, Adv. Funct. Mater. 2003, 13, $487-492$.

[14] P. G. Bruce, S. A. Freunberger, L. J. Hardwick, J.-M. Tarascon, Nat. Mater. 2012, 11, 19-29.

[15] D.-W. Wang, Q. Zeng, G. Zhou, L. Yin, F. Li, H.-M. Cheng, I. R. Gentle, G. Q. M. Lu, J. Mater. Chem. A 2013, 1, 9382 - 9394.

[16] X. Ji, K. T. Lee, L. F. Nazar, Nat. Mater. 2009, 8, 500-506.

[17] Y.-L. Lee, C.-H. Chang, J. Power Sources 2008, 185, 584-588.

[18] Z. Yang, C.-Y. Chen, C.-W. Liu, H.-T. Chang, Chem. Commun. 2010, 46, $5485-5487$.

[19] V. Chakrapani, D. Baker, P. V. Kamat, J. Am. Chem. Soc. 2011, 133, $9607-$ 9615.

[20] W. J. Chung, J. J. Griebel, E. T. Kim, H. Yoon, A. G. Simmonds, H. J. Ji, P. T. Dirlam, R. S. Glass, J. J. Wie, N. A. Nguyen, B. W. Guralnick, J. Park, A. Somogyi, P. Theato, M. E. Mackay, Y.-E. E. Sung, K. Char, J. Pyun, Nat. Chem. 2013, 5, 518-524.

[21] P. Liu, J. M. Gardner, L. Kloo, Chem. Commun. 2015, 51, 14660-14662.

[22] D. A. Boyd, C. C. Baker, J. D. Myers, V. Q. Nguyen, G. A. Drake, C. C. McClain, F. H. Kung, S. R. Bowman, W. Kim, J.S. Sanghera, Chem. Commun. 2017, 53, 259-262.

[23] E. Gabrielsson, H. Ellis, S. Feldt, H. Tian, G. Boschloo, H. Anders, S. Licheng, Adv. Energy Mater. 2013, 3, 16471656.

[24] G. Boschloo, A. Hagfeldt, Inorg. Chim. Acta 2008, 361, 729-734.

[25] J. Zhang, L. Yang, Y. Shen, B.-W. Park, Y. Hao, E. M. J. Johansson, G. Boschloo, L. Kloo, E. Gabrielsson, S. Licheng, A. Jarboui, C. Perruchot, M. Jouini, N. Vlachopoulos, H. Anders, J. Phys. Chem. C 2014, 118, 16591 16601.

[26] N. S. Manan, L. Aldous, Y. Alias, P. Murray, L. J. Yellowlees, M. C. Lagunas, C. Hardacre, J. Phys. Chem. B 2011, 115, 13873-13879.

[27] R. P. Martin, W. H. Doub, J. L. Roberts, D. T. Sawyer, Inorg. Chem. 1973, $12,1921-1925$.

[28] S. Zhang, X. Wang, Y. Su, Y. Qiu, Z. Zhang, X. Wang, Nat. Commun. 2014, $5,4127$.

[29] P. Liu, B. Xu, K. M. Karlsson, J. Zhang, N. Vlachopoulos, G. Boschloo, L. Sun, L. Kloo, J. Mater. Chem. A 2015, 3, 4420-4427.

[30] W. Yang, M. Pazoki, A. I. K. Eriksson, Y. Hao, G. Boschloo, Phys. Chem Chem. Phys. 2015, 17, 16744-16751.

[31] J. Zhang, Y. Hua, B. Xu, L. Yang, P. Liu, M. B. Johansson, N. Vlachopoulos, L. Kloo, G. Boschloo, E. M. J. Johansson, L. Sun, A. Hagfeldt, Adv. Energy Mater. 2016, 6, 1601062.

Manuscript received: February 28, 2017

Revised manuscript received: April 10, 2017

Accepted manuscript online: May 4, 2017

Version of record online: $\mathbf{\square} \mathbf{\square}, 2017$ 


\section{FULL PAPERS}

Doping S with Se: In a facile solventfree reaction, molten sulfur reacts with selenium disulfide and 1,3-diisopropenylbenzene to produce high-sulfur/selenium-content polymers. The polymers are solution-processable in common organic solvents and can be deposited onto photoelectrodes for use as holetransporting materials in solid-state dyesensitized solar cells and perovskite solar cells.

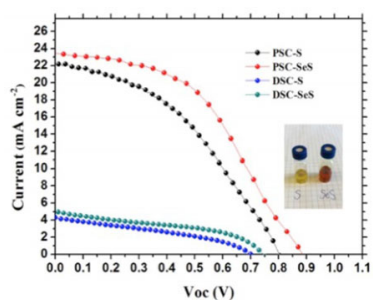

P. Liu, L. Kloo, J. M. Gardner*

Cross-Linked Sulfur-Selenium Polymers as Hole-Transporting Materials in Dye-Sensitized Solar Cells and Perovskite Solar Cells 